\title{
KCNQ1 gene polymorphisms are associated with lipid parameters in a Chinese Han population
}

\author{
Zhong Chen ${ }^{1 *+}$, Quanzhong Yin ${ }^{2 \dagger}$, Genshan Ma ${ }^{1}$, Qi Qian ${ }^{1}$
}

\begin{abstract}
Background: Four single nucleotide polymorphisms (SNPs) (rs2237892, rs2237895, rs2237897, and rs2283228) in KCNQ1 are reported to be associated with type 2 diabetes mellitus (T2DM), possibly caused by a reduction in insulin secretion and higher fasting glucose, but the results are inconsistent. We investigated whether these 4 genetic markers are associated with serum lipid metabolism in a middle-aged Chinese Han population.

Methods: We enrolled 398 consecutive patients, including 180 with premature coronary artery disease (CAD) (male $<55$ years, female < 65 years) and 218 controls without documented CAD. All subjects were genotyped for 4 SNPs by using the ligase detection reaction method. Fasting blood sugar (FBS) and plasma concentrations of total cholesterol, triglycerides (TG), high-density lipoprotein cholesterol (HDL-C), low-density lipoprotein cholesterol (LDLC), apolipoprotein A1 (apo A1), and apolipoprotein B (apo B) were determined by standard biochemical methods. Main anthropometric and metabolic characteristics are analyzed among 3 genotypes at rs2283228, rs2237895, rs2237897, or rs2237892 in KCNQ1.
\end{abstract}

Results: The 3 genotypes AA, AC, and CC were present in rs2283228 and rs2237895, and the 3 genotypes CC, CT, and $\Pi$ were present in rs2237897 and rs2237892. The minor genotypes CC at rs2283228 and $\Pi$ at rs2237892 were associated with higher levels of TG ( $P=0.007$ and 0.026 , respectively). Furthermore, subjects with the CC genotype at rs2283228 had lower levels of HDL-C and apo A1 than in the other 2 genotype groups $(P=0.052$ and 0.055 , respectively). No other associations were detected between these 4 SNPs and FBS or other lipid parameters.

Conclusions: Our data suggest that rs2283228 and rs2237892 in KCNQ1 are associated with lipid metabolism in a middle-aged Chinese Han population.

\section{Background}

$K C N Q 1$, which is located at chromosome 11p15.5 and near a candidate region at $11 \mathrm{p} 13-\mathrm{p} 12$ and mainly encodes a protein for a voltage-gated potassium channel required for the repolarization phase of the cardiac action potential, has been proved to be associated with type 2 diabetes mellitus (T2DM). Studies done by different groups show that some common single nucleotide polymorphisms (SNPs) in KCNQ1, acting as T2DM susceptibility genes, exist in different ancestral groups including in the Asian populations of the Japanese, Korean, and Chinese in Hong Kong and Shanghai [1-5]. Among these are the 4 common SNPs rs2237892,

\footnotetext{
* Correspondence: zhongchen7498@sina.com

+ Contributed equally

'Department of Cardiology, the Affiliated ZhongDa Hospital and Institute of Cardiovascular Disease of Southeast University, Nanjing 210009, P.R. China

Full list of author information is available at the end of the article
}

rs2237895, rs2237897, and rs2283228 that were well replicated. However, controversies still exist in which these SNPs in KCNQ1 are not implicated as T2DM susceptibility genes in individuals of European descent [6,7] or in a middle-aged population from East China [8].

Owing to the lack of consistent replication of these results in case-control studies in different study populations, it remains to be determined whether the results derived from Western societies are internationally applicable to East Asian races or specifically the Chinese Han population, or whether genetic background can cause different clinical phenotypes of the same disease as coronary artery disease (CAD) or T2DM.

Only recently have scholars demonstrated that the increased risk for T2DM linked to SNPs in KCNQ1 is likely to be caused by a reduction in insulin secretion, higher levels of fasting glucose or HbA1c $[5,9,10]$, which implies that the $K C N Q 1$ variants may play a major 
physiological role in the metabolism and dynamic balance of blood glucose. Furthermore, some other gene polymorphisms such as hepatocyte nuclear factor-1 homeobox A (HNF1A) gene polymorphisms [11], PPARgamma gene C161T polymorphism [12] and adiponectin receptor-2 gene variations [13] have also been proved to be connected with diabetes and cardiovascular disease.

Given that it is still unknown whether these 4 SNPs in $K C N Q 1$ are associated with plasma lipid parameters besides their inconsistent association with T2DM [1-10], to fill this knowledge gap, we aimed to determine whether these 4 common SNPs at KCNQ1 loci would correlate with plasma lipid parameters in a middle-aged Chinese Han population living in East China. The results will help solve this apparent controversy and provide new evidence to elucidate the mechanism of KCNQ1 variants on the risk of T2DM and CAD.

\section{Methods}

\section{Study population samples}

The study population has been previously described [8]. Briefly, from January 2003 to August 2008, 398 patients undergoing coronary angiography (CAG) for chest discomfort or suspected CAD were enrolled in this study, including 180 patients (men age 32-54 years and women age 39-64 years) with documented premature CAD [14] and 218 subjects without coronary stenosis, acting as controls. CAD was defined as a significant coronary stenosis ( $\geq 50 \%)$ in at least one of the 3 main coronary arteries or their major branches (branch diameter $\geq 2$ $\mathrm{mm}$ ) assessed by CAG or having experienced a myocardial infarction (MI) defined according to World Health Organization criteria. All patients with type 1 diabetes mellitus, congenital heart disease, syndrome $\mathrm{X}$, severe liver or kidney disease, or noncoronary artery thrombotic disease were excluded from this study. The study was approved by the Medical Ethics Committee of the Affiliated ZhongDa Hospital of Southeast University. Before enrollment, the trial information was explained carefully to each patient, and subsequently written informed consent was obtained from all participants.

\section{Coronary angiography}

All participants underwent CAG during hospitalization. The grade of the coronary stenosis and CAD diagnosis were judged by 2 cardiologists unaware of this study.

\section{Determination of parameters and risk factors}

At the time of enrollment, background data, such as sex, age, height, body weight, and risk factors including hypertension, T2DM, family history of CAD, and smoking status were collected from each subject. Anthropometric measurements and blood pressure determination were performed according to standard protocols. Blood was collected and plasma concentrations of total cholesterol (TC), triglycerides (TG), high-density lipoprotein cholesterol (HDL-C), and low-density lipoprotein cholesterol (LDL-C) were analyzed as previously described [15]. Levels of apolipoprotein A1 (apo A1), apolipoprotein B (apo B), fasting blood sugar (FBS), and insulin were determined by standard biochemical methods using a chemistry analyzer (Beckman Coulter Synchron clinical system LX20). Insulin resistance was calculated from fasting insulin and glucose by using the homeostasis model assessment method [16].

Determination of hypertension, T2DM, family history of CAD, and smoking status has been previously described [8]. Body weight and height were measured with individuals wearing light clothing, and body mass index (BMI) is expressed as weight in kilograms divided by the square of the height in meters.

\section{DNA extraction and genotyping}

Genomic DNA extraction and genotyping of 4 SNPs in intron 15 of KCNQ1 have been described previously [8]. Genotype distributions obeyed the Hardy-Weinberg equilibrium $(P>0.05)$.

\section{Statistical analyses}

Statistical analyses were conducted using SPSS 15.0 software. Continuous data are expressed as mean $\pm \mathrm{SD}$, and categorical variables are expressed as frequencies. Analyses of continuous data and categorical variables among 3 different groups according to the genotypes of these 4 SNPs at KCNQ1 were determined by one-way ANOVA or chi-square test. Two-tailed $P$-values $<0.05$ were considered as significant.

\section{Results}

Analysis of baseline characteristics in patients among 3 different genotypic groups (Table 1 and Table 2)

The 3 genotypes AA, AC, and CC are in rs2283228 and rs2237895, and the 3 genotypes CC, CT, and TT are in rs2237897 and rs2237892. When all study subjects were divided into 3 groups as the AA, AC, and CC group in rs2283228 and rs2237895, or the CC, CT, and TT group in rs2237897 and rs2237892, we found that 3 groups were well matched for mean age and gender composition. Subjects with the CC genotype in rs2283228 and TT genotype in rs2237892 had significantly higher levels of TG compared with the other 2 groups $(P<0.05)$, but this was not the case in subjects with the CC genotype in rs2237895 or TT genotype in rs2237897 (data not shown).

Overall in the study population, no significant differences were detected in the prevalences of hypertension, T2DM, family history of CAD, smoking, and average values of BMI, FBS, insulin, TC, LDL-C, and homeostasis model assessment of insulin resistance (HOMA-IR) 
Table 1 Comparisons of anthropometric and metabolic characteristics among 3 genotypes at rs2283228

\begin{tabular}{|c|c|c|c|c|}
\hline \multirow[b]{2}{*}{ rs 2283228} & \multirow[b]{2}{*}{ AA } & \multicolumn{2}{|c|}{ Genotype } & \multirow[t]{2}{*}{$P$} \\
\hline & & $A C$ & CC & \\
\hline Numbers & 156 & 191 & 51 & \\
\hline Sex, male $(n / \%)$ & $77 / 49.3$ & $90 / 47.1$ & $27 / 52.9$ & 0.746 \\
\hline Age, years & $51.67 \pm 5.50$ & $51.28 \pm 5.47$ & $52.53 \pm 5.72$ & 0.836 \\
\hline Hypertension, n/\% & $83 / 53.2$ & $121 / 63.3$ & $31 / 60.7$ & 0.155 \\
\hline Type 2 diabetes mellitus, n/\% & $21 / 13.5$ & $29 / 15.2$ & $7 / 13.7$ & 0.894 \\
\hline Family history of CAD, n/\% & $64 / 41.0$ & $73 / 38.2$ & $17 / 33.3$ & 0.609 \\
\hline Smokers, n/\% & $53 / 33.9$ & $69 / 36.1$ & $17 / 33.3$ & 0.887 \\
\hline $\mathrm{BMI}, \mathrm{kg} / \mathrm{m}^{2}$ & $24.29 \pm 3.46$ & $24.93 \pm 3.81$ & $24.33 \pm 3.00$ & 0.227 \\
\hline $\mathrm{FBS}, \mathrm{mmol} / \mathrm{L}$ & $5.73 \pm 1.72$ & $5.57 \pm 0.98$ & $5.87 \pm 1.86$ & 0.408 \\
\hline Insulin, mU/L & $14.31 \pm 11.87$ & $13.16 \pm 9.84$ & $17.32 \pm 13.08$ & 0.351 \\
\hline HOMA-IR & $3.64 \pm 0.59$ & $3.56 \pm 0.57$ & $4.36 \pm 0.83$ & 0.138 \\
\hline $\mathrm{TC}, \mathrm{mmol} / \mathrm{L}$ & $4.65 \pm 0.93$ & $4.39 \pm 0.86$ & $4.63 \pm 0.78$ & 0.116 \\
\hline $\mathrm{TG}, \mathrm{mmol} / \mathrm{L}$ & $1.53 \pm 0.76$ & $1.50 \pm 0.80$ & $2.03 \pm 0.84$ & 0.007 \\
\hline LDL-C, mmol/L & $2.82 \pm 0.80$ & $2.71 \pm 0.74$ & $2.74 \pm 0.84$ & 0.604 \\
\hline $\mathrm{HDL}-\mathrm{C}, \mathrm{mmol} / \mathrm{L}$ & $1.21 \pm 0.30$ & $1.14 \pm 0.25$ & $1.07 \pm 0.22$ & 0.052 \\
\hline Apo A1, g/L & $1.15 \pm 0.18$ & $1.11 \pm 0.19$ & $1.08 \pm 0.16$ & 0.055 \\
\hline Apo B, g/L & $0.87 \pm 0.25$ & $0.86 \pm 0.25$ & $0.97 \pm 0.23$ & 0.115 \\
\hline
\end{tabular}

Data are mean \pm SD, or number (\%), as appropriate.

$P$ is the significance level of comparison of clinical and plasma parameters among 3 groups by one-way ANOVA or chi-square test.

Apo A1, apolipoprotein A1; Apo B, apolipoprotein B; BMl, body mass index; CAD, coronary artery disease; FBS, fasting blood sugar; HDL-C, high-density lipoprotein cholesterol; HOMA-IR, homeostasis model assessment-insulin resistance; LDL-C, low-density lipoprotein cholesterol; SNPs, single nucleotide polymorphisms; TC, total cholesterol; TG, triglyceride.

among 3 groups according to 3 different genotypes at 4 SNPs in KCNQ1 (all $P>0.05$ ).

Despite the lack of association between genotypes and TC, LDL-C, and apo B, concentrations of HDL-C and apo A1 in the CC group in rs2283228 were lower at the borderline significance level compared with the other 2 groups $(P=0.052$ and 0.055 , respectively). No other associations were detected between concentrations of HDL-C, apo A1, and apo B and SNPs at rs2237892, rs2237895, or rs2237897 (all $P>0.05$ ).

Table 2 Comparisons of anthropometric and metabolic characteristics among 3 genotypes at rs2237892

\begin{tabular}{|c|c|c|c|c|}
\hline \multirow[b]{2}{*}{ rs2237892 } & \multirow[b]{2}{*}{ CC } & \multicolumn{2}{|c|}{ Genotype } & \multirow[t]{2}{*}{$P$} \\
\hline & & $C T$ & $\pi$ & \\
\hline Numbers & 189 & 168 & 41 & \\
\hline Sex, male (n/\%) & $92 / 48.7$ & $81 / 48.2$ & $21 / 51.2$ & 0.942 \\
\hline Age, years & $51.04 \pm 5.48$ & $51.96 \pm 5.50$ & $52.64 \pm 5.39$ & 0.864 \\
\hline Hypertension, n/\% & $106 / 56.1$ & $101 / 60.1$ & 28/68.3 & 0.330 \\
\hline Type 2 diabetes mellitus, n/\% & $27 / 14.3$ & $24 / 14.3$ & $6 / 14.6$ & 0.998 \\
\hline Family history of CAD, n/\% & $73 / 38.6$ & $63 / 37.5$ & $18 / 43.9$ & 0.752 \\
\hline Smokers, n/\% & $63 / 33.3$ & $61 / 36.3$ & $15 / 36.6$ & 0.818 \\
\hline $\mathrm{BMI}, \mathrm{kg} / \mathrm{m}^{2}$ & $24.34 \pm 3.35$ & $24.89 \pm 3.94$ & $24.59 \pm 3.00$ & 0.362 \\
\hline $\mathrm{FBS}, \mathrm{mmol} / \mathrm{L}$ & $5.73 \pm 1.61$ & $5.51 \pm 0.94$ & $6.04 \pm 2.01$ & 0.120 \\
\hline Insulin, mU/L & $13.70 \pm 11.28$ & $13.43 \pm 10.02$ & $18.66 \pm 13.04$ & 0.232 \\
\hline HOMA-IR & $3.68 \pm 0.69$ & $3.51 \pm 0.59$ & $4.78 \pm 0.81$ & 0.437 \\
\hline $\mathrm{TC}, \mathrm{mmol} / \mathrm{L}$ & $4.60 \pm 0.90$ & $4.41 \pm 0.90$ & $4.75 \pm 0.66$ & 0.157 \\
\hline $\mathrm{TG}, \mathrm{mmol} / \mathrm{L}$ & $1.60 \pm 0.83$ & $1.48 \pm 0.74$ & $2.01 \pm 0.87$ & 0.026 \\
\hline LDL-C, mmol/L & $2.77 \pm 0.78$ & $2.72 \pm 0.77$ & $2.85 \pm 0.82$ & 0.759 \\
\hline $\mathrm{HDL}-\mathrm{C}, \mathrm{mmol} / \mathrm{L}$ & $1.19 \pm 0.29$ & $1.14 \pm 0.25$ & $1.09 \pm 0.25$ & 0.178 \\
\hline Apo A1, g/L & $1.14 \pm 0.18$ & $1.08 \pm 0.19$ & $1.12 \pm 0.18$ & 0.095 \\
\hline Apo B, g/L & $0.88 \pm 0.26$ & $0.85 \pm 0.25$ & $0.92 \pm 0.21$ & 0.072 \\
\hline
\end{tabular}

Abbreviations see Table 1. 


\section{Discussion}

In the present study, for the first time, we report a strong association between rs2283228 and rs2237892 in KCNQ1 and lipid metabolism in a middle-aged Chinese Han population, which adds new data to this study issue.

Better understanding and preventive strategies for the morbidity and mortality related to T2DM are compelling. Recently, some susceptibility genes for T2DM have been reported [1-4], and potential mechanisms have also been elucidated $[5,9,10]$. However, inconsistent results still exist [6-8], and other mechanisms could not be fully excluded.

In the study by Tan JT et al [9], a total of 3734 participants (2 520 Chinese, 693 Malay, and 521 Asian Indians) living in Singapore were enrolled, among which 1881 Chinese subjects with normal glucose tolerance served as controls, and the reference population had an age range from 18 to 69 years. In the study by Liu Y et al [5], there were more women in both T2DM cases (women, 1 127; men, 785) and controls (women, 1 406; men, 635) and higher average age [(63.9 \pm 9.5$)$ years $v s$. $(58.1 \pm 9.4)$ years] than in our study. For the present study, all participants were aged 32 to 64 years and were hospitalized for CAD screening, among which $14.3 \%$ of subjects were diagnosed with T2DM, 180 subjects (45.2\%) had CAD, and 218 subjects (54.8\%) were non-CAD controls [8]. Young CAD patients usually have a different profile of major coronary risk factors [17]. Obviously, the differences in enrollment criteria and population characteristics account for the discrepancies between these studies. Meanwhile, differences in genetic inheritance among the races, lifestyles, public health insurance, and a system of free access to hospitals might contribute to the available subjects enrolled in our study.

In the current study, subjects in 3 groups according to different genotypes at rs2283228, rs2237895, rs2237897, and rs2237892 were well matched for mean age and gender composition, and no significant differences were detected in the prevalences of hypertension, T2DM, family history of CAD, smoking and values of BMI, FBS, insulin, TC, LDL-C, and HOMA-IR.

More recently, emerging evidence supports TG as a risk factor for CAD $[18,19]$. Patients with T2DM are more likely to have higher levels of TG and lower levels of HDL-C. Our study thus furthermore helps settle the issue of whether the variants in KCNQ1 are related to lipid metabolism. In the present study, we demonstrated that an association exists between CC genotype in rs2283228 and TT genotype in rs2237892 and higher levels of TG. Further fine mapping of SNPs in KCNQ1, especially within the LD block containing rs2283228 or rs2237892, may allow the eventual identification of the causal variant. Meanwhile, in the study by Giuffrida et al, though HNF1A I27L polymorphism did not differ significantly among late-onset autosomal dominant diabetes mellitus, classical T2DM and normoglycemic controls, it was found to be associated with risk of hypertriglyceridemia [11]. In patients with CAD combined with T2DM, P PARgamma C161 > T genotypes are associated with levels of TG and apo B but not glucose metabolism, with $\mathrm{CC}$ homozygote carriers having significantly higher levels of TG and apo B than those in $\mathrm{T}$ allele carriers [12]. Large prospective studies have identified HDL-C as a strong, independent, inverse predictor of risk of CAD [20,21]. Patients with higher levels of HDL-C and CAD had a similar or lower prevalence of traditional CAD risk factors compared with patients with normal HDL-C levels and CAD [22]. In our study, subjects with CC genotype in rs2283228 had lower levels of HDL-C and apo A1.

Some limitations of the present study need to be acknowledged. First, our study population comprised only those who have been admitted to the hospital for CAD screening and diagnosis, so it's more representative of patients in a cardiac center and might not be representative of the general population. Additionally, our study sample is predominantly yellow; thus, the results may not be generalizable to other ethnic groups in which disparities in population composition, geographical, and ethnic backgrounds may exist. It is well known that significant differences exist in the frequencies of some genetic variations among different ethnic groups and geographical regions. The fact is that these novel observations have not been previously found in other ethnic groups.

\section{Conclusion}

Our novel findings that the risk alleles of rs2283228 and rs2237892 within the KCNQ1 gene are associated with levels of TG, HDL-C and apo A1 in a middle-aged Chinese Han population are encouraging. Though the causal effects of four common SNPs (rs2237892, rs2237895, rs2237897, and rs2283228) in KCNQ1 on T2DM are controversial, our present study, for the first time, provide new evidence that these variants have an effect on lipid metabolism. Further studies are needed to firmly replicate these promising findings in other populations and to fully delineate the role of $K C N Q 1$ and its related pathways in the pathogenesis of T2DM and CAD.

\section{Abbreviations}

Apo A1: apolipoprotein A1; Apo B: apolipoprotein B; BMl: body mass index; CAD: coronary artery disease; CAG: coronary angiography; FBS: fasting blood sugar; HDL-C: high-density lipoprotein cholesterol; HNF1A: hepatocyte nuclear factor-1 homeobox A; HOMA-IR: homeostasis model assessment- 
insulin resistance; LDL-C: low-density lipoprotein cholesterol; SNPS: single nucleotide polymorphisms; TC: total cholesterol; TG: triglyceride; T2DM: type 2 diabetes mellitus.

\section{Acknowledgements}

We are grateful to Xiaoli Zhang and Jiahong Wang for their efforts on data collection.

\section{Author details}

${ }^{1}$ Department of Cardiology, the Affiliated ZhongDa Hospital and Institute of Cardiovascular Disease of Southeast University, Nanjing 210009, P.R. China. ${ }^{2}$ Department of Cardiology, the Affiliated Jiangyin Hospital of Southeast University, Jiangyin 214400, P.R.China.

\section{Authors' contributions}

ZC conceived the study, designed and performed the study experiments, analyzed the data and interpreted the results and wrote the manuscript. QZY, GSM and QQ interpreted the results, participated in the writing of the manuscript. All authors read and approved the final manuscript.

\section{Author information}

'Department of Cardiology, the Affiliated ZhongDa Hospital and Institute of Cardiovascular Disease of Southeast University, NO.87 Dingjiaqiao, Nanjing 210009, P.R.China

${ }^{2}$ Department of Cardiology, the Affiliated Jiangyin Hospital of Southeast University, Jiangyin 214400, P.R.China

\section{Competing interests}

The authors declare that they have no competing interests.

Received: 3 August 2010 Accepted: 11 August 2010

Published: 11 August 2010

\section{References}

1. Mori Y, Otabe S, Dina C, Yasuda K, Populaire C, Lecoeur C, Vatin V, Durand E, Hara K, Okada T, Tobe K, Boutin P, Kadowaki T, Froguel P: Genome-wide search for type 2 diabetes in Japanese affected sib-pairs confirms susceptibility genes on $3 q, 15 q$, and $20 q$ and identifies two new candidate loci on 7p and 11p. Diabetes 2002, 51:1247-1255.

2. Nawata H, Shirasawa S, Nakashima N, Araki E, Hashiguchi J, Miyake S, Yamauchi T, Hamaguchi K, Yoshimatsu H, Takeda H, Fukushima H, Sasahara T, Yamaguchi K, Sonoda N, Sonoda T, Matsumoto M, Tanaka Y, Sugimoto $H$, Tsubouchi $H$, Inoguchi T, Yanase T, Wake N, Narazaki K, Eto T, Umeda F, Nakazaki M, Ono J, Asano T, Ito Y, Akazawa S, et al: Genomewide linkage analysis of type 2 diabetes mellitus reconfirms the susceptibility locus on 11p13-p12 in Japanese. J Hum Genet 2004, 49:629-634.

3. Unoki H, Takahashi A, Kawaguchi T, Hara K, Horikoshi M, Andersen G, Ng DP, Holmkvist J, Borch-Johnsen K, Jørgensen T, Sandbaek A, Lauritzen T, Hansen T, Nurbaya S, Tsunoda T, Kubo M, Babazono T, Hirose H, Hayashi M, Iwamoto Y, Kashiwagi A, Kaku K, Kawamori R, Tai ES, Pedersen O, Kamatani N, Kadowaki T, Kikkawa R, Nakamura Y, Maeda S: SNPs in KCNQ1 are associated with susceptibility to type 2 diabetes in East Asian and European populations. Nat Genet 2008, 40:1098-1102.

4. Yasuda K, Miyake K, Horikawa Y, Hara K, Osawa H, Furuta H, Hirota Y, Mori H, Jonsson A, Sato Y, Yamagata K, Hinokio Y, Wang HY, Tanahashi T, Nakamura N, Oka Y, Iwasaki N, Iwamoto Y, Yamada Y, Seino Y, Maegawa H, Kashiwagi A, Takeda J, Maeda E, Shin HD, Cho YM, Park KS, Lee HK, Ng MC, $\mathrm{Ma} R$, et al: Variants in KCNQ1 are associated with susceptibility to type 2 diabetes mellitus. Nat Genet 2008, 40:1092-1097.

5. Liu Y, Zhou DZ, Zhang D, Chen Z, Zhao T, Zhang Z, Ning M, Hu X, Yang YF, Zhang ZF, Yu L, He L, Xu H: Variants in KCNQ1 are associated with susceptibility to type 2 diabetes in the population of mainland China. Diabetologia 2009, 52:1315-1321.

6. Diabetes Genetics Initiative of Broad Institute of Harvard and MIT Lund University, and Novartis Institutes of BioMedical Research, Saxena R, Voight BF, Lyssenko V, Burtt NP, de Bakker PI, Chen H, Roix JJ, Kathiresan S, Hirschhorn JN, Daly MJ, Hughes TE, Groop L, Altshuler D, Almgren P, Florez JC, Meyer J, Ardlie K, Bengtsson Boström K, Isomaa B, Lettre G, Lindblad U, Lyon HN, Melander O, Newton-Cheh C, Nilsson P, OrhoMelander M, Råstam L, Speliotes EK, Taskinen MR, Tuomi T, et al: Genome- wide association analysis identifies loci for type 2 diabetes and triglyceride levels. Science 2007, 316:1331-1336.

7. Zeggini $E$, Weedon MN, Lindgren CM, Frayling TM, Elliott KS, Lango $H$, Timpson NJ, Perry JR, Rayner NW, Freathy RM, Barrett JC, Shields B, Morris AP, Ellard S, Groves CJ, Harries LW, Marchini JL, Owen KR, Knight B, Cardon LR, Walker M, Hitman GA, Morris AD, Doney AS, Wellcome Trust Case Control Consortium (WTCCC), McCarthy MI, Hattersley AT: Replication of genome-wide association signals in U.K. samples reveals risk loci for type 2 diabetes. Science 2007, 316:1336-1341.

8. Chen Z, Zhang X, Ma G, Qian Q, Yao Y: Association study of four variants in KCNQ1 with type 2 diabetes mellitus and premature coronary artery disease in a Chinese population. Mol Biol Rep 2010, 37:207-212.

9. Tan JT, Nurbaya S, Gardner D, Ye S, Tai ES, Ng DP: Genetic variation in KCNQ1 associates with fasting glucose and beta-cell function: a study of 3,734 subjects comprising three ethnicities living in Singapore. Diabetes 2009, 58:1445-1449.

10. Hu C, Wang C, Zhang R, Ma X, Wang J, Lu J, Qin W, Bao Y, Xiang K, Jia W: Variations in KCNQ1 are associated with type 2 diabetes and beta cell function in a Chinese population. Diabetologia 2009, 52:1322-1325.

11. Giuffrida FM, Furuzawa GK, Kasamatsu TS, Oliveira MM, Reis AF, Dib SA: HNF1A gene polymorphisms and cardiovascular risk factors in individuals with late-onset autosomal dominant diabetes: a crosssectional study. Cardiovasc Diabetol 2009, 8:28.

12. Wan J, Xiong S, Chao S, Xiao J, Ma Y, Wang J, Roy S: PPARgamma gene C161T substitution alters lipid profile in Chinese patients with coronary artery disease and type 2 diabetes mellitus. Cardiovasc Diabetol 2010, 9:13.

13. Halvatsiotis I, Tsiotra PC, Ikonomidis I, Kollias A, Mitrou P, Maratou E, Boutati E, Lekakis J, Dimitriadis G, Economopoulos T, Kremastinos DT, Raptis SA: Genetic variation in the adiponectin receptor 2 (ADIPOR2) gene is associated with coronary artery disease and increased ADIPOR2 expression in peripheral monocytes. Cardiovasc Diabetol 2010, 9:10.

14. Kareinen A, Viitanen L, Halonen P, Lehto S, Laakso M: Cardiovascular risk factors associated with insulin resistance cluster in families with earlyonset coronary artery disease. Arterioscler Thromb Vasc Biol 2001, 21:1346-1352.

15. Chen Z, Ma G, Zhang X, Wang J: Lipoprotein lipase and premature coronary artery disease. Acta Cardiol 2009, 64:379-383.

16. Matthews DR, Hosker JP, Rudenski AS, Naylor BA, Treacher DF, Turner RC: Homeostasis model assessment: insulin resistance and beta-cell function from fasting plasma glucose and insulin concentrations in man. Diabetologia 1985, 28:412-419.

17. Yasar AS, Turhan H, Basar N, Metin F, Erbay AR, Ilkay E, Sabah I: Comparison of major coronary risk factors in female and male patients with premature coronary artery disease. Acta Cardiol 2008, 63:19-25.

18. Hopkins PN, Wu LL, Hunt SC, Brinton EA: Plasma triglycerides and type II hyperlipidemia are independently associated with premature familial coronary artery disease. J Am Coll Cardiol 2005, 45:1003-1012.

19. Chen CY, Hwu CM, Lin MW, Tsai CH, Yeh HI: High triglyceride level is associated with severe coronary artery disease in hypertensive subjects. Scand CardiovasC J 2008, 42:146-152.

20. Gordon T, Castelli WP, Hjortland MC, Kannel WB, Dawber TR: High density lipoprotein as a protective factor against coronary heart disease: the Framingham study. Am J Med 1977, 62:707-714.

21. Assmann G, Schulte $H$, von Eckardstein A, Huang Y: High-density lipoprotein cholesterol as a predictor of coronary heart disease risk: the PROCAM experience and pathophysiological implications for reverse cholesterol transport. Atherosclerosis 1996, 124(suppl):S11-20.

22. DeFaria Yeh D, Freeman MW, Meigs JB, Grant RW: Risk factors for coronary artery disease in patients with elevated high-density lipoprotein cholesterol. Am J Cardiol 2007, 99:1-4.

doi:10.1186/1475-2840-9-35

Cite this article as: Chen et al:: KCNQ1 gene polymorphisms are associated with lipid parameters in a Chinese Han population. Cardiovascular Diabetology 2010 9:35. 